\title{
The Use of Information and Communication Technology (ICT) for Knowledge Management in the Second Cycle Educational Institutions in Ghana
}

\author{
Patrick Ohemeng Gyaase \\ Faculty of Information and \\ Communication Science \& \\ Technology, Catholic University \\ College of Ghana, Fiapre \\ P O Box 363, Sunyani, Ghana
}

\author{
Edward Twum Anane \\ Faculty of Economic and \\ Business Administration \\ Catholic University College of \\ Ghana, Fiapre \\ P O Box 363, Sunyani, Ghana
}

\author{
Isadore Nii Attoh Armah \\ Project Coordinator (ILO-IPEC/ \\ CCP/PPP), International Cocoa \\ Initiative (ICl), East Legon, Accra
}

\begin{abstract}
Given its capabilities to widen access, improve the quality and reduce the cost of developing, accessing and maintaining information, Information and Communication Technology (ICT) offers increased possibilities for managing knowledge. This paper thus investigates the level of utilization of ICT in the knowledge management processes in the Ghanaian educational system. Being a descriptive study, a randomly selected sample of second cycle educational institutions was surveyed through questionnaire. Using descriptive data analysis, the study found a low level of Information and Communication Technologies usage in knowledge management processes in the second cycle educational system. Knowledge management practices were found to be inefficient due to, among other things, absence of strategic policies and nonutilization of ICT. The findings indicate that the Secondary Schools are not deriving the efficiency returns of the computers they have acquired due to the absence of a deliberate and effective strategy for knowledge management. Also students, teachers and administrators in the second cycle schools are not benefitting from the information revolution for knowledge management. It was recommended that capacity building in knowledge management and improvement of Internet speed should be given priority attention by educational authorities.
\end{abstract}

\section{General Terms}

Knowledge Management, Information Technology; New Economy

\section{Keywords}

Knowledge, Management, ICT, Education, Technology

\section{INTRODUCTION}

Knowledge is displacing natural resources, capital, and labour as the basic economic resource in the 'new economy' [1] Contemporary themes of strategic management stress that an organization's competitive advantage flows from its unique knowledge and how it manages it. It is therefore argued that the only sustainable competitive advantage in the future will be effective and efficient organizational knowledge management [2]. Knowledge management is generally described as any process or practice of creating, acquiring, capturing, sharing and using knowledge, wherever it resides, to enhance learning and performance in organizations [3].Knowledge management is an ancient phenomenon. The competences of employees and how they are combined into organisational capabilities has always been a key to economic performance and smart managers have always been aware of the need to utilise and develop knowledge in the interest of the organization [4] [5]The indispensability of ICT is evidenced in its versatility and applicability in all human endeavours especially in educational institutions whose core functions are teaching, learning, research, extension service, administration and knowledge management [6]. Computers, the Internet and the social media are seen as powerful enabling tools for educational change and reform. ICT is a diverse set of technological tools and resources used for creating, storing, managing and communicating information. ICT has formidable capabilities and could be a cost effective development tool especially for education by facilitating teaching, learning, administration and management [7].

There is little doubt that the information technology revolution has fundamentally changed the role of knowledge in the economy. It has provided inexpensive and worldwide access to rich sources of information and offered new tools both for handling information and for advancing processes of knowledge creation and innovation. Therefore it is not surprising that knowledge management for some scholars and experts primarily signifies the use of advanced software, the codification of tacit knowledge and knowledge sharing through information systems [8].

One of the most vital resources of today's organization is the collective knowledge residing in the minds of that organization's employees, customers, and vendors. Managing such organizational knowledge has the potential benefit of leveraging core business competencies, accelerating innovation, decision-making, strengthening organizational commitment and building sustainable competitive advantage [9].

Educational institutions must therefore seek innovative means of collecting, disseminating and sharing knowledge and to understand how to transform that knowledge into effective decision making. This will ensure improvements in student learning outcomes [10]. The concern with student learning outcomes and achievements in education is not new in an era where there are strong external and internal demands for accountability and improvements of student learning outcomes. This study therefore seeks to assess the level of utilization of ICT for knowledge management to improve learning outcomes in the second cycle institutions of the Ghanaian educational Sector. 


\section{ICT AND KNOWLEDGE MANAGEMENT IN EDUCATIONAL INSTITUTIONS}

Educational institutions are organizations charged with achieving educational objectives such as the transfer of knowledge to students through exchanges between students and educators, students and books or other resources and among the students themselves. Educational institutions therefore face the challenge of how to create, store and share information and knowledge among people within the organization [9].

Educational institutions are often described as knowledgepoor because of the difficulties in enabling the schools and the teachers jointly develop and implement knowledge about their work and performance [11].The potential of ICT to facilitate knowledge management processes efficiently and effectively in education cannot be overemphasized [12]

Information and Communication Technology refers to the equipment and software elements that facilitate accessibility, retrieval, storage, organization, manipulation and presentation of information by electronic means [13]. ICT provides increased possibilities for codification of knowledge and innovations in teaching activities by facilitating the delivery of learning and cognitive activities anywhere at any time. ICT advances knowledge by widening access to education, improving the quality of education and reducing cost [14]. Incorporating ICT in knowledge management in second cycle education in Ghana is therefore imperative.

ICT provides tools to enhance teaching, learning, research and the management of educational institutions. Hence, access to ICT tools has become a matter of critical importance for any educational institution that seeks to become viable and effective for educating students, producing and disseminating knowledge and preparing the next generation of citizens with adequate skills [13]. The wide applicability of ICT tools such as repository of books, communication, teaching and learning, maintenance of students' records, personnel and financial records makes them indispensable in the educational enterprise [15].

The Ghana ICT4AD policy statement envisions the transformation of Ghana into an information-rich knowledge-based society and economy through the development, deployment and exploitation of ICT within the economy and society. The Policy places high emphasis on ICT in education and commits the government to a comprehensive programme for rapid deployment; utilization and exploitation of ICTs within the educational system [16].

\subsection{Knowledge Management Concepts}

Knowledge is referred to as information that enables action and decisions or information with direction. Whereas data refer to bare facts devoid of context, information is data in context, and knowledge is information that facilitates action. Knowledge can thus be defined as justified beliefs about relationships among concepts relevant to a particular area [17].

There are two fundamental types of knowledge namely, tacit and explicit knowledge. Tacit knowledge resides in the minds of people and is either impossible or difficult to articulate. This type of knowledge is underutilized because it is not readily available to the organization. Tacit knowledge includes insights, intuitions, and hunches. It is personal and based on individual experiences and activities [18] .
Explicit knowledge on the other hand exists in the form of words, sentences, documents, organized data, and computer programs among other explicit forms [19]. The fundamental problem of knowledge management (KM) is to explicate tacit knowledge and make it available to others for use. It is possible to convert explicit knowledge into tacit and vice versa. An essential characteristic of knowledge is its explicitness so that it can be stored and transferred to others [20].

\subsection{Knowledge Management Processes and Enablers}

Knowledge Management Systems (KMS) ensure that organizations get the most out of knowledge resources [18]. It is defined as tools, processes and practices of creating, acquiring, capturing, sharing and using knowledge, wherever it resides, to enhance learning and performance in organizations. These processes cover creating, capturing, and using knowledge to enhance organisational performance [21] and managing, storing, valuing and distributing the knowledge [22].

Knowledge management aims at enhancing the extent to which knowledge facilitates the achievement of individual or organizational goals through discovery, capturing, sharing and applying knowledge [23]. Among the benefits of knowledge management systems are the ability to share valuable organizational knowledge, the avoidance of reinventing the wheel, reduction of training time for new employees, and the retention of intellectual property after the employee leaves the organization provided such knowledge can be codified [24]. Knowledge management systems provide users with access to organizational knowledge. Equally important is the users' ability to use the knowledge once it is accessed and to subsequently share it with others [25].

Knowledge management enablers can be technological or organizational. These enablers are systems and infrastructures which ensure that knowledge is created, captured, transferred and shared [26]. Technological enablers include expert systems, knowledge bases, various types of information management, software, document management systems and other information technology (IT) systems supporting organizational knowledge flows [26].

The advent of the Internet has created additional enabling technologies, including e-learning, web-conferencing, collaborative software, content management systems, corporate directories, email lists, wikis and blogs [27].

Organisational enablers for knowledge management include communities of practice, networks of practice, before, after and during action reviews, peer assists, information taxonomies, coaching and mentoring.

\subsection{The Importance of Knowledge Management in Education}

Educational institutions are under tremendous pressure for increased accountability from external and internal sources. Externally, stakeholders such as employers, government agencies, and parents are seeking measurable improvements in educational institutions and are demanding information about students' learning outcome [28].

Internally, educational institutions are responding by asking themselves difficult questions of how to improve upon teaching and student's learning. As organizations committed to educational missions, finding ways to ensure students acquire knowledge effectively and efficiently is imperative. 
This requires that teachers and facilities to deliver the requisite information to the students for improved learning. Educational institutions stand to reap enormous benefit with the adoption of Knowledge Management systems so as to meet both external and internal demands [29].

Certain individual educators possess knowledge on various fields of study which facilitates students' performance in these fields. Traditionally the challenge has been how to convert the knowledge that resides in this individual and make it easily accessible to other educators. With the innovations and capabilities offered by ICT, both explicit and tacit knowledge can be shared for the benefit of the institution [30].

Knowledge management in education therefore involves the development and implementation of policies and practices that would facilitate the collection of information and sharing it to ensure that individual members of the institution can access such skills, ideas and experiences through the use of ICT to improve learning environments and outcomes [14]. This requires the development and integration of structures and systems of knowledge management into educational institutions to improve their performance. Knowledge management systems provide an enabling environment for research, curriculum development, student and alumni services, administration, strategic planning, and traditional classroom enhancement [31] [22].

Knowledge management has been identified as an effective tool in curriculum development process. The process includes curriculum design and revision efforts, knowledge of teaching and learning with technology, pedagogy and assessment techniques, student evaluations and feedback [12].

Furthermore, knowledge management enables educators to create and represent quality knowledge for students to advance and improve their learning as well as turning tacit knowledge into explicit knowledge for the students [10]. The extent to which educators can transform their tacit knowledge into explicit knowledge thus depends on the existence of knowledge management system where knowledge or information concerning teaching methods and notes of experienced teachers are catalogued for any other teacher to access [32].

Knowledge management system would also enable new staff make appropriate decisions to ensure that their courses, topics, instructional materials, presentations, assignments and assessments are updated to improve student teaching [33].

\section{THEORETICAL FRAMEWORK FOR THE STUDY}

For educational institutions to effectively utilize knowledge management systems, three key resources of the institution must inter-play efficiently to deliver the required outcome. These resources are the people, processes, and technologies within the institution [34]

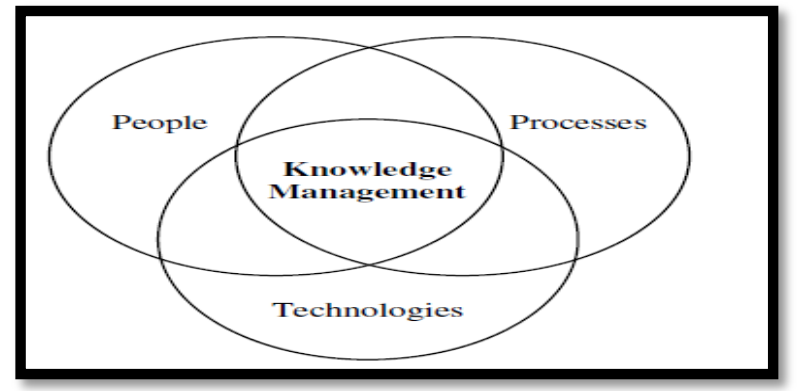

Fig 1: Key Resources of Knowledge Management [34]

\subsection{People}

People are the originators and managers of knowledge in organization. Managing knowledge requires that managers of educational institutions develop effective mechanisms for the capturing, collecting and transferring of relevant knowledge within the institution to improve services, outcomes and performances. Knowledge management practices thus encourage and engage people at the institutional level to share with others what they know, and what they are learning through collegial and professional teamwork [35]. Working groups of staff and educators from across departments could be persuaded to collaborate on common themes and exchange information to address the concerns of students, institutions, parents and to meet societal expectations [36] [37].

These kinds of informal, self-sustaining collegial bodies often referred to as communities of practice have been around for a long time and have provided an effective mechanism to manage tacit knowledge within organisations. These mechanisms of knowledge management supported by modern ICT application have proved to be at the centre of innovation in education [28].

\subsection{Processes}

Institutional processes such as administrative procedures, curriculum development processes, information sharing patterns and information silos affect information flow within every organization [34]. An effective knowledge management system should enable members of the institution to access information when needed and share information with others who may benefit from it. Curriculum development and school management processes could be facilitated by knowledge management systems to create quality knowledge and the transfer of knowledge to improve student learning outcomes [15].

\subsection{Technologies}

Information and Communication Technology is a very effective technology for knowledge management and should be broadly accessible to target user groups to promote the tracking and exchange of useful information within and across institutions [34]. The Internet facilitates e-learning, web and video conferencing, collaborative software, content management systems, email lists, wikis and blogs that provide effective means for the capture and transfer of knowledge. These platforms have become effective enablers of knowledge management practices in educational institutions [38].The use of ICT in knowledge management thus creates opportunities for advancing and improving students' learning outcomes by creating quality knowledge [39]. 


\section{METHODOLOGY}

This study uses a descriptive approach to assess the factors influencing the use of ICT for knowledge management in second cycle schools of the educational system in Ghana. Descriptive studies have important roles in educational research since they greatly increase knowledge about what happens in schools [40]. Descriptive research uses surveys and other fact-finding enquiries with the purpose of describing the state of affairs as it exists at present [41].

To effectively undertake this study, questionnaires were used to elicit information to determine and assess the utilisation of ICT for knowledge management in the core functions of educational institutions in Ghana. The target population were the teachers and the administrators of second cycle institutions in Ghana. The questionnaires were sent to fifty (50) administrative staff and hundred (100) teachers, totalling (one hundred and fifty (150) respondents from 20 second cycle institutions using random sampling. Out of the hundred and fifty (150), ninety (90) responses were received, thirty (60) from teachers and sixty (30) from administrators.

Pre-test of the questionnaire was carried out with some teachers and administrative staff of one of the sampled senior high schools. Piloting helped in refining the questionnaire to ensure the reliability and validity of the findings of the study [42]. The questionnaires were administered after a review based on the comments from the pilot participants. Face-to-face interview and inspection of ICT infrastructure were also undertaken for the clarification of some of the issues raised by the respondents.

\subsection{Data Presentation and Analysis}

Descriptive analysis of the responses was done using Microsoft Excel and presented in Tables and Bar charts.

\subsubsection{The Level of ICT skills of the Respondents}

Effective utilization of ICT in knowledge management requires computerisation and the stakeholders should be able to use ICT in their work. The study therefore sought to establish the level of ICT literacy among the respondents. The responses are presented in fig 2 below. In the case of teachers, 28 rated themselves as having intermediate skills, 15 have beginners' skills, and 11 consider themselves proficient while 6 have no ICT literacy. With regard to the administrators 9 possess intermediate skills, 9 with beginner skills, 8 are proficient and 4 no ICT skills. ICT literacy levels among the people in the educational environment are crucial since proficient users in the educational sector could be the catalyst for the use of ICT in knowledge management process [14].

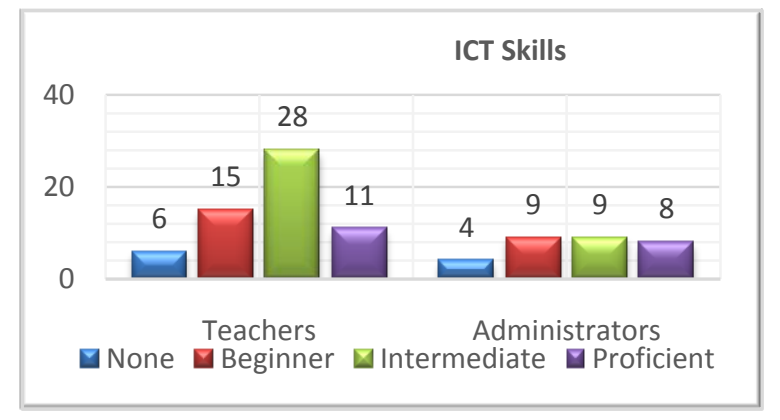

Fig 2: ICT Literacy Level among the Respondents

\subsubsection{Access to Computers and the Internet}

Access to ICT facilities is a pre-requisite for its utilization for knowledge management in education. This study therefore sought to determine the respondents' access to ICT facilities namely computers and the Internet in their line of duty. $31(52 \%)$ of the teachers indicated that they do not have access to computers whilst $29(48 \%)$ have access to a computer. For the school administrators, 23 out of the 30 have access to computers whilst only 7 did not. Having access to computers to work greatly increases the chances that employees will be likely to actively engage themselves in knowledge management activities.For access to the Internet, 24 and 39 of administrators and teachers respectively indicated that they have access to Internet at work. This is quite important because the Internet is considered one of the vital enablers in the performance of knowledge management activities.

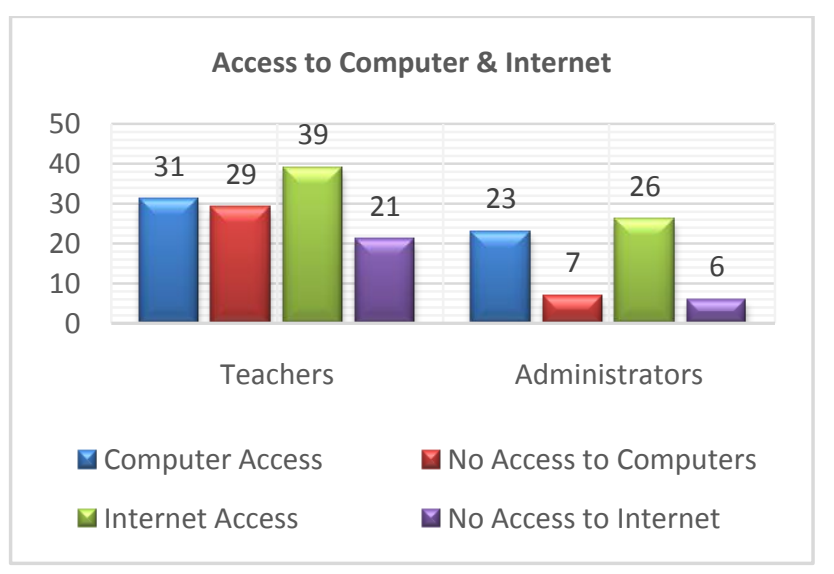

Figure 3: Access to Computers and Internet

\subsection{Use of ICT in Knowledge Management Processes}

To identify the extent of ICT utilization in the various knowledge management activities, respondents were asked how information is captured and stored in their institutions. They were also asked about how information and knowledge are communicated and shared and the extent to which ICT is used in these activities. The results are presented below.

\subsubsection{Information storage}

The data presented in Table 1 indicates that $57 \%$ and $67 \%$ of teachers and administrators respectively stored their information on school computers. This means that teachers and administrators do not have access to this information outside the institutions. None of the respondents stores information on a network environment or in an institutional repository. Although the presence of computers is facilitating storage and access of information, the current information storage practices are not ideal since they do not encourage the sharing of information. The availability of institutional information repository is one of the prime requisites of knowledge management.

Table 1: Means of Information Storage

\begin{tabular}{|l|l|l|l|l|l|l|}
\hline \multirow{2}{*}{} & \multicolumn{2}{|l|}{ Teachers } & \multicolumn{2}{l|}{ Admin } & \multicolumn{2}{l|}{ Total } \\
\cline { 2 - 8 } & No & $\%$ & $\begin{array}{l}\text { N } \\
\text { o }\end{array}$ & $\%$ & No & $\%$ \\
\hline Networked drives & 0 & $0 \%$ & 0 & $0 \%$ & 0 & $0 \%$ \\
\hline Personal Computers & 8 & $13 \%$ & 0 & $0 \%$ & 8 & $9 \%$ \\
\hline
\end{tabular}




\begin{tabular}{|l|l|l|l|l|l|l|}
\hline School Computers & 34 & $57 \%$ & 20 & $\begin{array}{l}67 \\
\%\end{array}$ & 54 & $60 \%$ \\
\hline $\begin{array}{l}\text { External storage } \\
\text { devices }\end{array}$ & 4 & $7 \%$ & 1 & $3 \%$ & 5 & $6 \%$ \\
\hline $\begin{array}{l}\text { Remote or online } \\
\text { back-up services }\end{array}$ & 0 & $0 \%$ & 0 & $0 \%$ & 0 & $0 \%$ \\
\hline $\begin{array}{l}\text { Hardcopies in } \\
\text { folders / cupboards }\end{array}$ & 8 & $13 \%$ & 7 & $\begin{array}{l}23 \\
\%\end{array}$ & 15 & $17 \%$ \\
\hline Written documents & 6 & $10 \%$ & 2 & $7 \%$ & 8 & $9 \%$ \\
\hline TOTAL & $\mathbf{6 0}$ & $\begin{array}{l}\mathbf{1 0 0} \\
\mathbf{\%}\end{array}$ & $\mathbf{3 0}$ & $\begin{array}{l}\mathbf{1 0 0} \\
\mathbf{\%}\end{array}$ & $\mathbf{9 0}$ & $\begin{array}{l}\mathbf{1 0 0} \\
\mathbf{\%}\end{array}$ \\
\hline
\end{tabular}

\subsubsection{Knowledge Communication and}

\section{Dissemination}

Communication of knowledge either from individuals within an institution or between institutions play a significant role in knowledge management. Fig 4 below presents the state of the information communication and knowledge sharing practices in the educational institutions surveyed. The responses show reliance on printed sheet for communication, 38 and 24 of the responding teachers and administrators respectively despite the availability of electronic communication channel. In addition to cost of paper and printers, non-electronic information communication constitutes a significant constraint to effective knowledge management.

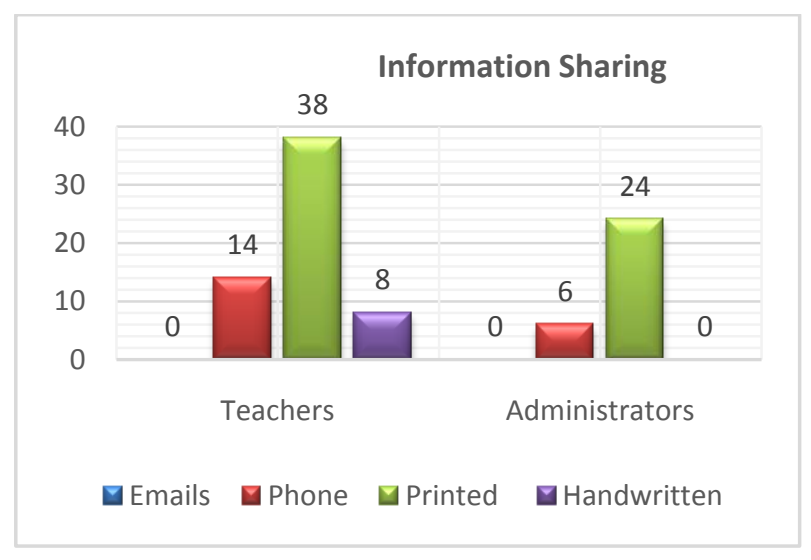

Fig 4: Knowledge and Information Sharing

An effective knowledge management system requires a comprehensive set of communication tools to support discussion, possible collaborations and provide a means for adapting and integrating materials from one project into another [43]. The clear absence of the use of emails indicates that none of the respondents uses Internet for official communication in the institutions. This situation is therefore hindering effective knowledge management in these institutions.

\subsubsection{Reasons for Manual Information Management}

Out the 60 teacher respondents, 21 (35\%) identified unavailability of ICT equipment as a major problem, 13 $(22 \%)$ of them said it takes a longer time to obtain and learn how to use such equipment as the reasons for not using ICT in their knowledge management activities. Other reasons identified are limited skilled staff and lack of access to quality Internet connectivity.

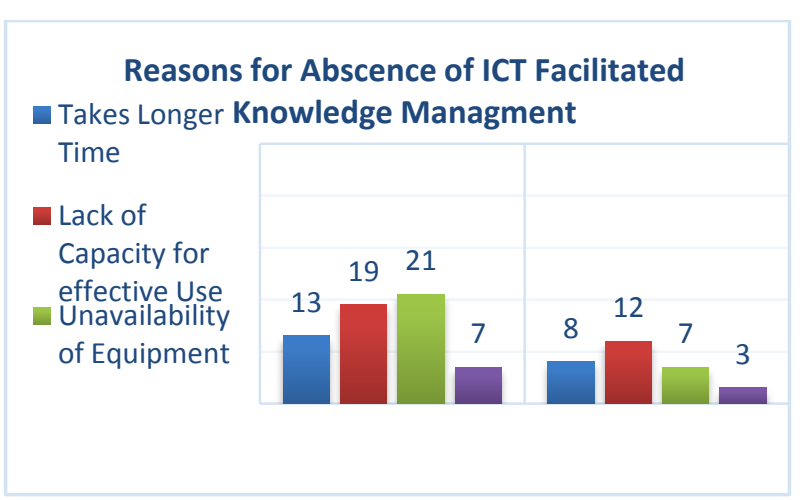

Fig 5: Reasons for Manual Knowledge Management Practices

\section{FINDINGS}

Information and Communications Technology (ICT) is an important ingredient of virtually every successful knowledge management program. The level of Utilization of ICT for knowledge management activities such as the discovery, capture, storage, distribution, communication and application of knowledge in second cycle educational institutions in Ghana remains disappointingly low among both teachers and administrators. The three types of barriers to knowledge namely; temporal distance, physical distance and social distance [44] can be overcome through the use of ICT thereby bridging the gap between education in the cities and the rural areas.

The low level of ICT use in knowledge management in the second cycle education in Ghana also affects the access to information that is relevant beyond the individual level which may prove helpful for other individuals in the institutions. ICT in the second cycle educational institutions in Ghana is characterised by standalone computers which are not networked and used by individuals with no possibility of any electronic document sharing.

Accessibility of computers and Internet connectivity remain disturbingly low. The implication is that workers and students alike are being denied access to such an important educational tool which is a sine qua non in teaching and learning and other important knowledge management activities.

\section{CONCLUSION}

For educational institutions in Ghana to benefit from both explicit and tacit knowledge for the achievement of their educational objectives, serious attention should be given to the utilization of ICT in knowledge management. The current practices where a change in subject teacher or and administrator could result in the downward achievement of students could be a thing of the past if efforts are made toward effective management of the institutional knowledge. The establishment of information repositories would be a step in the right direction.

As a matter of urgency, effort should be redirected from distributing computers to schools and individuals in the educational sector to the provision of quality network and Internet infrastructures for the educational institutions in the country. The absence of this essential infrastructure is affecting the effective use of the limited number of computers available to the respondents in this study.

On the whole, the practice of knowledge management in the schools' operations was not encouraging. It was abysmally low in teaching and learning, among others. The ICT 
knowledge-base of both some teachers and administrative staff was too low to enable them adopt and harness the massive resources that ICT provides. And finally there were inadequate management support and motivation to personnel for deliberate implementation of a knowledge management system.

\section{RECOMMENDATIONS}

In the light of the low level of access to ICT facilities among teachers and the administrative staff of the secondary schools, it is recommended that the various stakeholders in the second cycle educational system namely, the Government, Ghana Education Service and Ministry of Education should make the diffusion of ICT applications in knowledge management in second cycle institutions in Ghana a priority. The deployment of ICT-based knowledge management systems would offer significant advantages over informal networks to enable teachers and administrators share new knowledge among themselves.

The absence of deliberate knowledge management plans and strategies also calls the capacity building of institutions to develop a clear vision of knowledge management processes through participatory approach to ensure staff acceptance. There is also the need to develop skills of teachers and administrators to handle knowledge effectively using ICT. This would further enhance the development of knowledge sharing culture, where people would share information and their experiences and are rewarded for doing so. The Ghana Education Service should provide a facility or guarantee for teachers and administrators to acquire personal computers to facilitate effective knowledge management in their institutions. Periodic training and seminars would also improve their skills and motivation to utilize ICT in their line of work.

Access to the Internet is probably the most critical resource at the disposal of modern educational institutions. The Ghana government should therefore motivate the Internet Service Providers (ISPs) to provide cheaper Internet service to second cycle educational institutions to facilitate effective knowledge management activities. Also the institutions need to provide adequate resources for qualified staff to effectively manage institutional repositories. These would transform the second cycle education system into knowledge-based and technology driven institutions for the achievement of students learning outcomes.

\section{REFERENCES}

[1] P.F. Drucker , "The new productivity challenge," Quality in Higher Education, vol. 37, 1995.

[2] M. R. Lee and Y.-C. Lan, "Toward a unified knowledge management model for SMEs," Expert Systems with Applications, pp. 729-735, 2011.

[3] L. Prusak, Knowledge in organizations. , Elsevier, 1997.

[4] L. A. Joia, "Measuring intangible corporate assets: linking business strategy with intellectual capital," Journal of Intellectual Capital, vol. 1, no. 1, pp. 68-84, 2000.

[5] B.-A. Lundvall, "Why the new economy is a learning economy," Techno-economic Paradigms: Essays in Honour of Carlota Perez, pp. 221-238, 2009.

[6] R. Maier and T. Hädrich., Knowledge Management Systems, 2011, pp. 779-790.

[7] C. Abbott, ICT: Changing education, Routledge, 2000.
[8] V. Venkaiah and . P. Drucker, Leadership in a Globalised Economic Era: Some Perspectives and Challenges, 2013.

[9] J. Gary and E. Sallis, Knowledge management in education: Enhancing learning \& education, Routledge, 2013.

[10] M. Leask and N. Pachler, Eds., Learning to Teach Using ICT in the Secondary School: a companion to school experience, Routledge, 2013.

[11] OECD, Organisation for Economic Co-operation and Development. Education at a Glance 2010: OECD Indicators, OECD Pub, 2010.

[12] W. Omona, T. Van der Weider and J. Lubega, "Using ICT to enhance Knowledge Management in higher education," International Journal of Education \& Development using Information \& Communication Technology, vol. 6, no. 4, 2010.

[13] O. A. Adubifa, Towards the introduction and application of information and communication technologies in African universities, 2001.

[14] D. Ho, "Research, Innovation and Knowledge Management: the ICT Factor." commissioned paper for the UNESCO Forum on Higher Education, Research and Knowledge," UNESCO, Paris, 2007.

[15] M. Easterby-Smith and M. . A. Lyles, Handbook of organizational learning and knowledge management, John Wiley \& Sons, 2011.

[16] C. K. Dzidonu, "An Intergrated ICT-Led Socio Economic Development Policy Plan Development Framework," United Nations Economic Commission for Africa, Accra, 2003.

[17] Nonaka, "A dynamic theory of organizational knowledge creation," Organization science, vol. 5, no. 1, pp. 14-37, 1994

[18] I. Becerra-Fernandez and R. Sabherwal, Knowledge management: systems and processes, ME Sharpe, 2010.

[19] T. De Jong and M. G. Ferguson-Hessler, "Types and qualities of knowledge," Educational psychologist, vol. 31, no. 2, pp. 105-113., 1996.

[20] O. Renn, "The contribution of different types of knowledge towards understanding, sharing andcommunication risk concepts," Catalan Journal of Communication \& Cultural Studies, vol. 2, no. 2, pp. 177-195, 2010.

[21] T. . H. Davenport and L. Prusak, Working knowledge: Managing what your organization knows, MA: Harvard Business School Press, Boston, 1998.

[22] I. Dediana and L. Aroyo, "Knowledge Management for Networked Learning Environments: Applying Intelligent Agents," http://projects.edte.utwente.nl/proo/italo.htm, 1998

[23] M. Alavi and . A. Tiwana, ". "Knowledge management: the information technology dimension," The Blackwell handbook of organizational learning and knowledge management, pp. 104-21, 2003.

[24] Y. M. C. Yeh, "The implementation of knowledge management system in Taiwan's higher education," Journal of College Teaching \& Learning (TLC), vol. 2, no. $9,2011$. 
[25] W.-T. Lee, H. Shin-Yuan and P. Y. Chau, "Influence of knowledge management infrastructure on innovative business processes and market-interrelationship performance: An empirical study of hospitals in Taiwan," Journal of Global Information Management (JGIM), vol. 19, no. 2, pp. 67-89, 2011.

[26] U. R. Kulkarni and R. D. Freeze, ""Measuring Knowledge Management Capabilities," pp. 1090-1100, 2011.

[27] N. Sultan, "Knowledge management in the age of cloud computing and Web 2.0: Experiencing the power of disruptive innovations," International journal of information management, vol. 33, no. 1, pp. 160-165, 2013.

[28] K. W. Chu, M. Wang and A. . H. Yuen, "Implementing knowledge management in school environment: Teachers' perception," Knowledge Management \& ELearning: An International Journal (KM\&EL), vol. 3, no. 2, pp. 139-152, 2011.

[29] G. Kebede, "Knowledge management: An information science perspective," International Journal of Information Management, vol. 30, no. 5, pp. 416-424, 2010.

[30] K. E. Hoque, R. S. A. Samad, S. Siraj and A. Ziyadh, "The Role of ICT in school management of Maldives," Czesław Kupisiewicz, vol. 270, 2012.

[31] J. J. Kidwell, K. M. Vander Linde, S. L. Johnson and G. Bernbom , "Applying corporate knowledge management practices in higher education. Information Alchemy: The Art and Science of Knowledge Management," EDUCAUSE Leadership Series, vol. 3, pp. 1-24, 2001.

[32] H. Uzunboylu, . E. Hasan and Z. Ozcinar, "Results of a citation analysis of knowledge management in education," British Journal of Educational Technology, vol. 42, no. 3, pp. 527-538, 2011.

[33] R. . D. Johnson, "Information management as an enabler of knowledge management maturity: a South African perspective," International Journal of Information Management, vol. 30, no. 1, pp. 57-67, 2010.
[34] L. A. Petrides and T. R. Nodine, Knowledge Management in Education: Defining the Landscape, 2003.

[35] M. S. Saud, B. Shu'aibu, N. Yahaya and M. Yasin, "Effective integration of information and communication technologies (ICTs) in technical and vocational education and training (TVET) toward knowledge management in the changing world of work," African Journal of Business Management, vol. 5, no. 16, pp. 6668-6673, 2011.

[36] J. Ferguson, M. Huysman and M. Soekij, "Knowledge management in practice: Pitfalls and potentials for development," World Development, pp. 1797-1810, 2010.

[37] D. Hislop, Knowledge management in organizations: A critical introduction, Oxford: Oxford University Press, 2013.

[38] D. Rodríguez-Gómez and J. Gairín, "Unravelling knowledge creation and management in educational organisations: barriers and enablers," Knowledge Management Research \& Practice, 2013.

[39] V. Sharma, "A perceptual study on KM orientation in Indian private engineering institutions," International Journal of Educational Management, vol. 26, no. 3, pp. 234-251, 2012.

[40] R. K. Yin, Case Study Research: Design and Methods, Third Edition, Applied Social Research Methods Series, 3rd ed., London: SAGE Publications, 1994.

[41] M. Saunders, P. Lewis and A. Thornhill, Research Methods for Business Students, London: Financial Times Pitman Publishing, 1997.

[42] S. Sarantakos, Working with social research, Palgrave Macmillan, 1998.

[43] [43] C. W. Choo, B. Detlor and D. Turnbull, "Web Work: Information Seeking And Knowledge Work On The World Wide Web," Information Science And Knowledge Management, p. 236, 2000.

[44] R. Ruggles, "The State of the Notion: KNOWLEDGE MANAGEMENT IN PRACTICE.," California management review, vol. 40, no. 3, 1998 . 